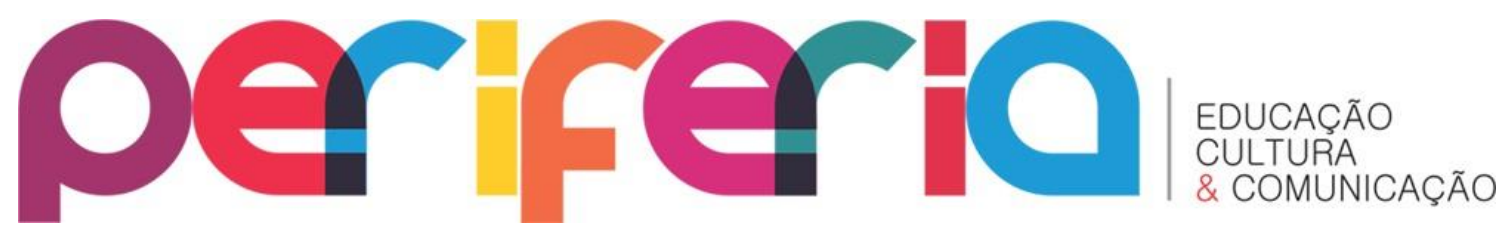

ISSN:1984-9540

DOI: 10.12957/periferia.2021.55931

\title{
EDUCAÇÃO NO CAMPO: reflexões sobre cidadania e cultura
}

\author{
Arlindo Lins de Melo Júnior ${ }^{1}$ \\ Luiz Bezerra Neto ${ }^{2}$
}

\section{Resumo}

A educação no campo encontra-se ligada à escolarização das populações rurais e, neste cenário campesino, é ela que faz a mediação na prática social de homens e mulheres para conquista da cidadania e acesso à cultura na sociedade. Nosso artigo teve como objetivo discutir a educação no campo refletindo sobre cidadania e cultura na perspectiva marxista. O método é o materialismo histórico-dialético. Além disso, utilizamos a pesquisa descritivo-exploratória, caracterizada como um processo metodológico baseado na seleção criteriosa de material bibliográfico. Os resultados demonstram que a cidadania é um direito inerente aos cidadãos que residem no campo, dado no âmbito das políticas brasileiras, como por exemplo: Brasil (1996). Já a cultura, faz parte da historicidade humana, trazendo em seu bojo os conhecimentos eruditos e os conhecimentos tradicionais herdados pelas populações do campo, como as atividades culturais que também são associadas às experiências que os homens e as mulheres do campo desenvolveram em um meio de vida simbiótico com a terra. Concluímos que ainda existem muitas pesquisas a serem realizadas sobre a temática da cidadania e da cultura na perspectiva das populações que pertencem ao campo, principalmente naquilo que diz respeito às atividades culturais por eles herdadas ou criadas.

Palavras-chave: Educação no Campo; Populações Tradicionais; Cultura Camponesa.

\footnotetext{
${ }^{1}$ Doutorando e mestre em Educação pela Universidade Federal de São Carlos (UFSCar). Licenciado em Educação Física pela Faculdade Claretiano. Atualmente é membro do Grupo de Estudos e Pesquisas sobre Educação no Campo - (GEPEC/HISTEDBR). Faz uso do referencial teórico savianista para analisar e compreender a educação do campo (na demanda da comunidade caiçara). ORCID: https://orcid.org/0000-0003-2391-4772. E-mail: arlindolins@yahoo.com.br

2 Professor da Universidade Federal de São Carlos (UFSCar) atuando na graduação e na pós-graduação. Membro de corpo editorial da Revista Eletrônica de Ciências da Educação (RECE) e da Revista de Educação (REVEDUC). É coordenador do Grupo de Estudos e Pesquisas sobre Educação no Campo (GEPEC) e coordenador do curso de pedagogia da terra da UFSCar. Tem experiência na área de Educação, com ênfase em Fundamentos da Educação. Atuando principalmente nos seguintes temas: educação rural, escola normal rural, movimento dos trabalhadores rurais sem-terra, ruralismo pedagógico. ORCID: https://orcid.org/0000-0002-6388-3467. E-mail: lbezerra.ufscar@gmail.com
} 


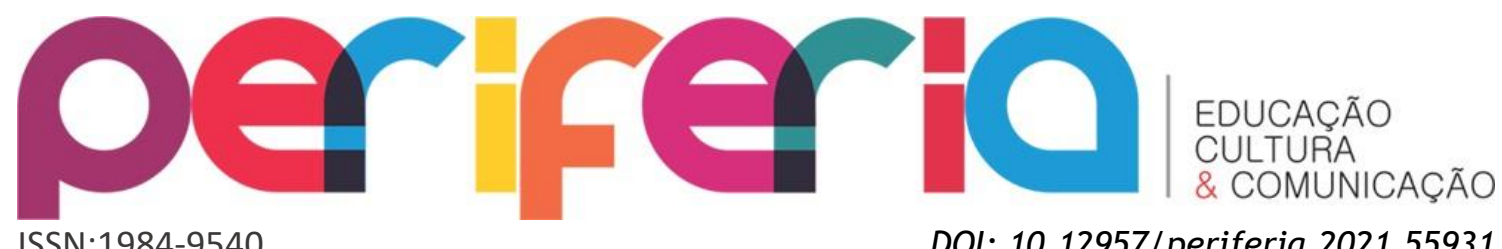

EDUCATION IN THE FIELD: reflections on citizenship and culture

\section{Abstract}

Education in the countryside is linked to the schooling of rural populations and, in this rural setting, it is the mediation in the social practice of men and women to achieve citizenship and access to culture in society. Our article aimed to discuss education in / from the countryside, reflecting on citizenship and culture from a Marxist perspective. The method is historical-dialectical materialism. In addition, we use descriptive-exploratory research, characterized as a methodological process based on the careful selection of bibliographic material. The results demonstrate that citizenship is an inherent right to citizens residing in the countryside, given within the scope of Brazilian policies, such as: Brasil (1996). Culture, on the other hand, is part of human historicity, bringing within it the erudite knowledge and traditional knowledge inherited by rural populations, such as cultural activities that are also associated with the experiences that rural men and women have developed in an environment of symbiotic life with the earth. We conclude that there is still a lot of research to be carried out on the theme of citizenship and culture from the perspective of the populations that belong to the countryside, especially with regard to the cultural activities inherited or created by them.

Keywords: Rural Education; Traditional Populations; Peasant Culture.

\section{EDUCACIÓN EN EL CAMPO: reflexiones sobre ciudadanía y cultura}

\section{Resumen}

La educación en el campo está ligada a la escolarización de las poblaciones rurales $y$, en este ámbito rural, es la mediación en la práctica social de hombres y mujeres para lograr la ciudadanía y el acceso a la cultura en la sociedad. Nuestro artículo tuvo como objetivo discutir la educación en / desde el campo, reflexionando sobre ciudadanía y cultura desde una perspectiva marxista. El método es el materialismo histórico-dialéctico. Además, utilizamos la investigación descriptiva-exploratoria, caracterizada como un proceso metodológico basado en la cuidadosa selección de material bibliográfico. Los resultados demuestran que la ciudadanía es un derecho inherente a los ciudadanos residentes en el campo, dado en el ámbito de las políticas brasileñas, tales como: Brasil (1996). La cultura, por su parte, forma parte de la historicidad humana, trayendo consigo los conocimientos eruditos y tradicionales 


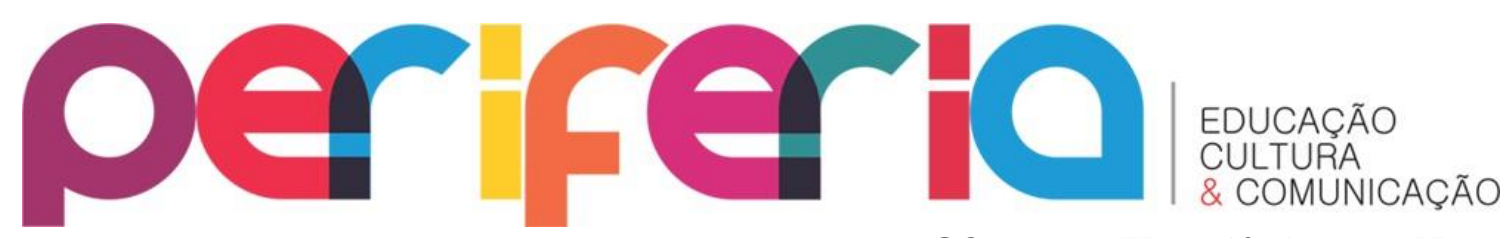

ISSN:1984-9540

DOI: $10.12957 /$ periferia. 2021.55931

heredados por las poblaciones rurales, como las actividades culturales que también están asociadas a las experiencias que los hombres y mujeres rurales han desarrollado en un entorno de simbiosis. vida con la tierra. Concluimos que aún queda mucha investigación por realizar sobre el tema de ciudadanía y cultura desde la perspectiva de las poblaciones que pertenecen al campo, especialmente en lo que respecta a las actividades culturales heredadas o creadas por ellas.

Palabras clave: Educación rural; Poblaciones Tradicionales; Cultura campesina.

\section{INTRODUÇÃO}

Pensar em educação no campo é refletir sobre a escolarização das populações que habitam no meio rural. Essa modalidade de ensino tem como alvo atender às demandas educacionais de indivíduos que vivem e trabalham no campo, esses homens e mulheres trazem em suas reivindicações político-sociais uma incansável busca por melhores perspectivas de vida em sociedade, neste sentido, o papel da educação é fomentar aos seres humanos que dela se utilizam um senso crítico no tocante aos aspectos econômicos, políticos e sociais, e assim, consequentemente, essas pessoas se encontrarão aptas a tomarem decisões no meio em que vivem alcançando com isso uma determinada forma de cidadania.

Nas políticas educacionais podemos observar aquelas destinadas às populações que compõem o campo. A Resolução $n^{\circ} 2$, de 28 de abril de 2008, do Ministério da educação, aparece como uma política que estabelece diretrizes complementares, normas e princípios para o desenvolvimento de políticas públicas de atendimento da educação básica do campo e, aponta que:

a Educação do Campo compreende a Educação Básica em suas etapas de Educação Infantil, Ensino Fundamental, Ensino Médio e Educação Profissional Técnica de nível médio integrada com o Ensino Médio e destina-se ao atendimento às populações rurais em suas mais variadas formas de produção da vida - agricultores familiares, extrativistas, pescadores artesanais, ribeirinhos, assentados e acampados da Reforma Agrária, quilombolas, caiçaras, indígenas e outros (BRASIL, 2008, p. 01). 


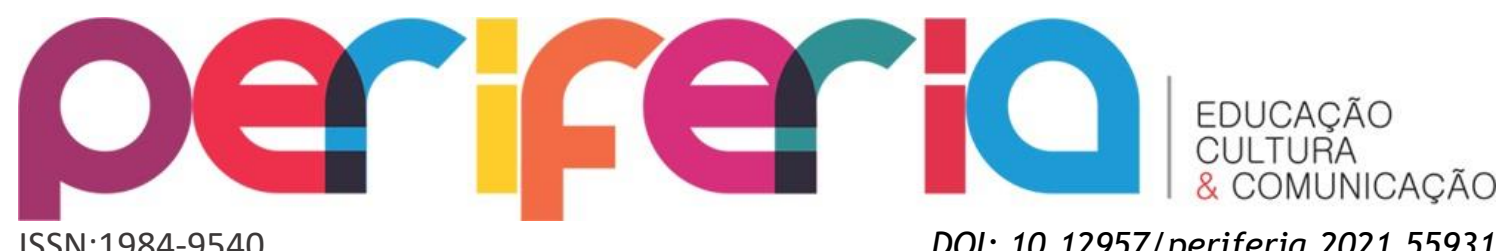

ISSN:1984-9540

DOI: 10.12957/periferia.2021.55931

Uma das características peculiares das populações pertencentes aos grupos que devem ter acesso à educação do $/ \mathrm{no}^{3}$ campo se constitui na defesa por um modelo sustentável de agricultura, sobretudo para as plantações de arroz, mandioca e feijão, dentre outros alimentos, tendo esta sustentabilidade como uma marca de boas práticas desta agricultura familiar.

Para estas populações, a lei de Diretrizes e Bases da Educação (LDB), em seu artigo 2, traz em seu bojo princípios e fins da educação brasileira que encontram-se como responsabilidade "da família e do Estado, inspirada nos princípios de liberdade e nos ideais de solidariedade humana, tem por finalidade o pleno desenvolvimento do educando, seu preparo para o exercício da cidadania e sua qualificação para o trabalho" (BRASIL, 1996).

$\mathrm{Na}$ educação no campo tanto cidadania como cultura encontram-se indissociavelmente ligadas à atividade material dos seres humanos por meio de suas representações, ideias, normas, valores, que aparecem como produto da atividade vital dos homens e das mulheres residentes no campo e cidade, e, de suas relações com seus iguais e com a natureza.

O presente artigo possui como fundamentação teórico-metodológica o Materialismo Histórico-Dialético. Para dar conta da análise, trabalharemos também com a estratégia metodológica descritivo-exploratória, caracterizada como um processo metodológico baseado na busca criteriosa de materiais bibliográficos minuciosamente eleitos por um pesquisador com experiência na temática abordada. Assim, procura-se explorar a realidade na qual o pesquisador está inserido, buscando fomentar novos conhecimentos fundamentados em um paradigma teóricometodológico (ZANELLA, 2013).

Neste sentido, o descritivo e o exploratório se entrelaçam na medida em que procuram se aprofundar no determinado fenômeno no intuito de refletirem as questões do problema pesquisado e trazerem novas respostas e hipóteses sobre o tema em questão (ZANELLA, 2013).

Ao selecionar os textos, o pesquisador realiza uma coleta de material bibliográfico que deve estar em harmonia com a fundamentação teórico-metodológica

\footnotetext{
${ }^{3}$ A diferenciação entre os termos do e no campo, foi aprofundada em Bezerra Neto (2010).
} 


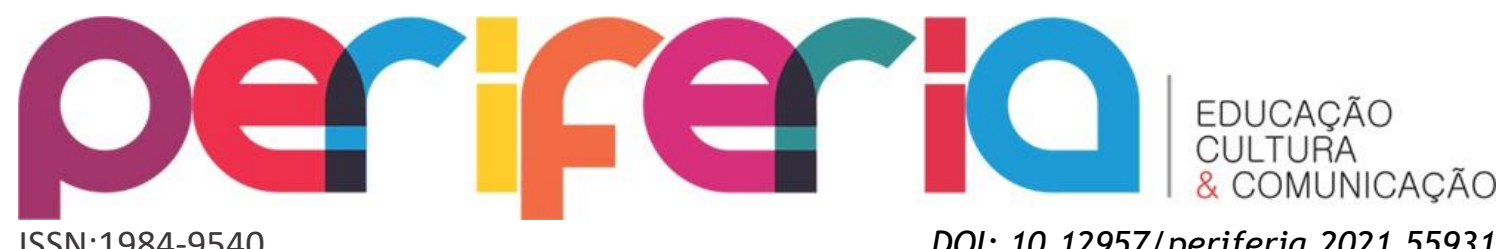

do Materialismo Histórico-Dialético. Desta maneira, temos como objetivo analisar a educação no campo refletindo sobre o caráter da cidadania e da cultura numa perspectiva marxista.

O artigo encontra-se dividido em três eixos temáticos, a seguir: (I) A educação no campo; (II) Refletindo sobre cidadania na educação no campo e (III) Refletindo sobre cultura na educação no campo: Um olhar para as atividades culturais.

\section{A EDUCAÇÃO NO CAMPO}

A função da educação “é tornar os indivíduos contemporâneos à sua época, pois, quando vêm ao mundo, os membros da espécie humana já se encontram num contexto que é produto histórico, isto é, produto das ações das gerações precedentes" (SAVIANI, 2016, p. 17). Desta forma, o modo de produção encontra-se conectado a um modo de cooperação ou a um estado social determinado decorrente de um conjunto das forças produtivas acessíveis aos seres humanos pelo capital e, com isso, determina o seu estado social (LOMBARDI, 2006).

Assim, a historicidade dos homens do campo ou da cidade encontra-se correlacionada à produção econômica, a qual desemboca em uma totalidade social cujos aspectos políticos, sociais, econômicos, culturais e educacionais estão ligados. Evidenciamos que os seres humanos, ao nascerem, são influenciados pelas condições do meio físico e social que, por sua vez, independem da época em que o indivíduo esteja, neste aspecto, ele já traz algumas determinações sociais, que devem ser absorvidas e compreendidas a partir dos conhecimentos produzidos pela humanidade e expressos em domínios científicos como a geologia, geografia, agronomia assim como pelo complexo das ciências físico-químicas e naturais. (SAVIANI, 2016).

Neste sentido, se a existência humana não é garantida pela natureza, ela tem de ser produzida historicamente pelos próprios homens, o que significa que aquilo que chamamos de natureza humana não é algo dado ao homem, mas é por ele produzido sobre a base da natureza biofísica (SAVIANI, 2016). Sabemos que:

A terra, seu celeiro primitivo, é também seu arsenal primitivo de meios de trabalho. Fornece-lhe, por exemplo, a pedra que lança e 


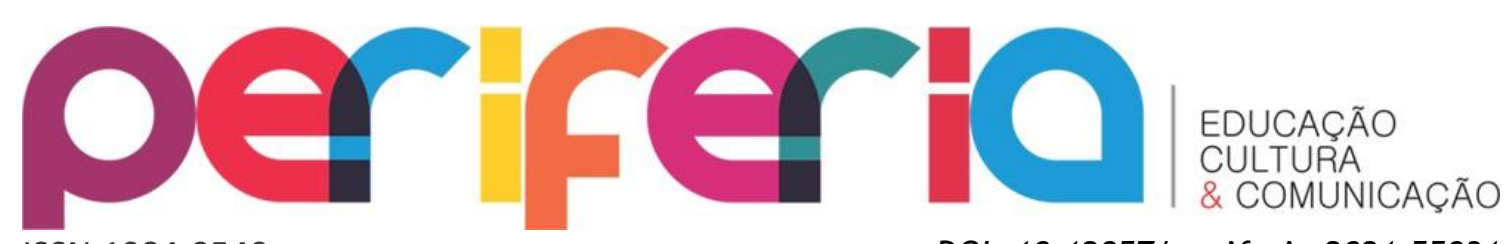

ISSN:1984-9540

DOI: 10.12957/periferia.2021.55931

lhe serve para moer, prensar, cortar etc. A própria terra é um meio de trabalho, mas, para servir como tal na agricultura, pressupõe toda uma série de outros meios de trabalho e um desenvolvimento relativamente elevado da força de trabalho. (MARX, 2015, p. 56-57).

Quando pensamos na distribuição dos meios de produção ${ }^{4}$, é preciso ter claro que em nossa nação, particularmente, prevaleceu a grande propriedade agravando o problema agrário caracterizado pela enorme concentração da propriedade da terra; pelo uso predatório da mesma e dos recursos naturais de modo geral; pela secundarização da produção de alimentos reservando-se as melhores terras para a monocultura destinada à exportação, o que vem resultando no agravamento da fome que tem assolado dezenas de milhões de brasileiros ao longo de muitas décadas; pela migração forçada que obriga grande número de camponeses a se mudarem para as cidades ou regiões distantes; pela produção de bens e insumos agroindustriais de iniciativa de empresas multinacionais, lançando mão de sementes transgênicas e fazendo largo uso de agrotóxicos que poluem o meio ambiente e envenenam os alimentos (SAVIANI, 2016).

Essa situação se acentuou com as políticas neoliberais que vieram a ser adotadas a partir dos anos de 1990 até os dias atuais, beneficiando os sucessores das antigas oligarquias rurais que se fortalecem politicamente, formando grande bancada no "Congresso Nacional e se impondo pela ideologia e pela força bruta, agravando os conflitos no campo marcados por assassinatos de líderes populares, de dirigentes dos sindicatos de trabalhadores e dos movimentos sociais" (SAVIANI, 2016, p. 34). Neste contexto trazido pelos movimentos sociais, as populações residentes no campo também clamavam por melhor educação, como forma de nortear o futuro de seus filhos e filhas.

Essa luta não foi fácil, uma vez que, para a população campesina, o sistema educacional sempre foi ainda mais perverso, permitindo a existência de prédios escolares em condições miseráveis e professores como uma formação inadequada para o exercício da profissão (BEZERRA NETO, 2012). A quantidade de horas-aulas era

\footnotetext{
${ }^{4}$ Neste sentido, terra enquanto meio de produção (terra-mercadoria), considerando a posse privada e os modelos de produção adotados. Importante ainda considerar que ao longo de toda a história do processo de ocupação e exploração econômica do território brasileiro, foram os ciclos econômicos vigentes a cada período (recortes temporais) que deram dinamicidade a esse processo.
}

Periferia, v. 13, n. 1, p. 84-100, jan./abr. 2021 


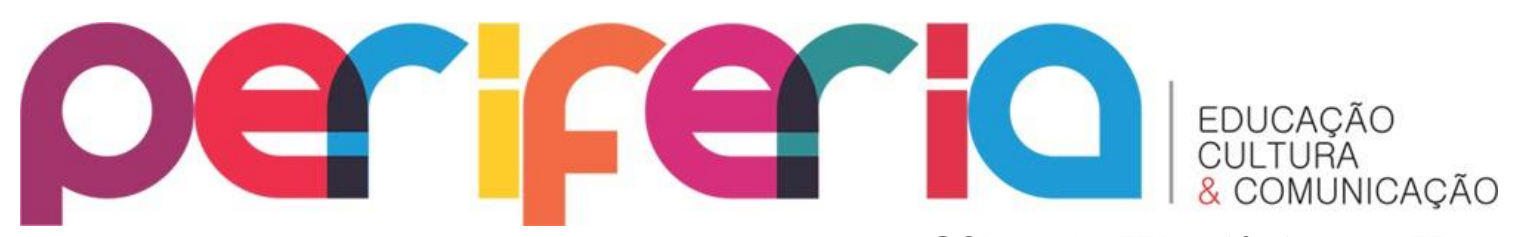

ISSN:1984-9540

DOI: $10.12957 /$ periferia.2021.55931

insignificante, pouco ou quase nenhum investimento em recursos pedagógicos, infraestrutura inadequada e sem falar que muitas vezes a manutenção dessas escolas ficava a cargo dos profissionais da educação ou do fazendeiro (BEZERRA NETO, 2012).

É ainda neste contexto que se inicia a luta de classes no campo, contrariando os grandes proprietários organizados na Confederação da Agricultura e Pecuária do Brasil que naquele momento representava 27 federações estaduais e 2142 sindicatos rurais espalhados por nossa nação, com força emergem líderes sindicais que convocam os trabalhadores rurais e pequenos agricultores a se engajarem na luta dada nos movimentos sociais rurais entre os quais se destaca o Movimento dos Trabalhadores Rurais Sem Terra (MST) (SAVIANI, 2016).

Apesar destes conflitos e até mesmo devido a eles, com o assassinato de dezenas de trabalhadores rurais (aqui destacamos a chacina de Eldorado dos Carajás), na década de 1990 e início do século XXI, apareceu um movimento autodenominado “Por uma Educação do Campo", reivindicando uma educação específica para o setor.

A discussão sobre educação no campo torna-se mais relevante na medida em que o campo brasileiro está longe de ser homogêneo e seus habitantes congregam interesses bastante divergentes, senão vejamos: os movimentos sociais basicamente se relacionam com os assentados por programas de reforma agrária, no entanto, temos trabalhadores remanescentes de quilombolas, pequenos proprietários, caiçaras, ribeirinhos que chegaram a determinadas regiões a partir do processo de migração ocorrido ao longo dos séculos XIX e XX, e outros agricultores que habitam determinadas regiões do país há várias décadas, até há centenas de anos e que não se relacionam com os movimentos sociais.

Ao se discutir sobre a luta pela terra é preciso compreender que o MST é um movimento que surgiu como herdeiro da bandeira antes levantada por outros sujeitos políticos que escreveram suas reivindicações em torno da luta pela terra, mas concomitantemente também se diferencia desses mesmos sujeitos, tanto na estrutura organizativa como nas estratégias de luta, dado que a conjuntura que mediou seu nascimento é diferente das anteriores (SILVA, 2019).

É neste sentido que devemos compreender as discussões do movimento por uma educação no campo, que veio alertar sobre as formas como o meio rural era abandonado pelo pelos administradores públicos. Questiona-se, no entanto, a defesa 


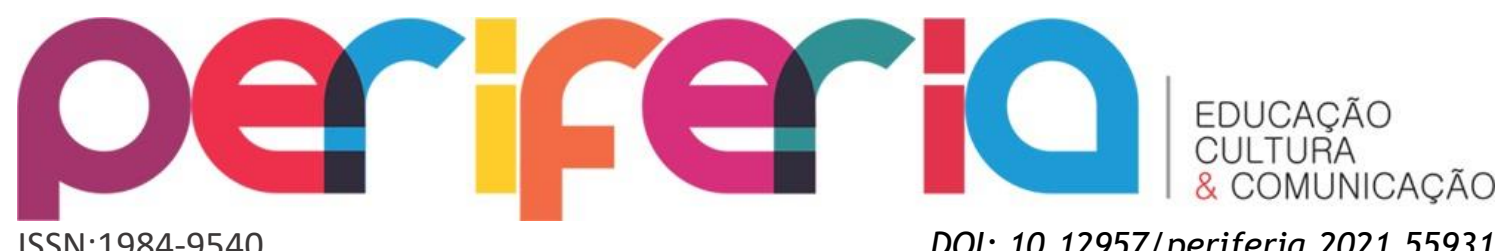

de um currículo específico incentivado por tal movimento, pois, com isto, correr-seia o risco de termos para estes setores uma educação diferenciada, aumentando o apartheid social, dado que as possibilidades de ingresso no ensino superior, a partir destas especificidades poderiam se ampliar.

O Movimento dos Trabalhadores Rurais Sem Terra optou por unificar a luta pela reforma agrária e pela educação numa única estrutura de organização que simultaneamente mantivesse a unidade ao passo que fosse possível se capilarizar por todo o território nacional, além de pretender ser um sujeito coletivo de massas, haja vista compreender ganhar mais força na ação com essa estratégia. "Além do mais adotou a ocupação da terra como a principal maneira de manifestar suas reivindicações" (SILVA, 2019, p. 64).

Em se pensando nos princípios educativos, o MST tem reafirmado seus desafios para uma escolarização e formação contra-hegemônica. Assim, sua estrutura organizativa se encontra de maneira descentralizada. A direção do movimento tem como intuito desburocratizar e dotar o MST de uma democracia mais viva e horizontal, permitindo maior agilidade na condução e ação política. Assim, o movimento apresenta alguns setores de atividade responsáveis pela dinâmica de gestão e organização de suas ações. Esses setores se organizam por tipos de ações, sendo divididos em: setor de produção, frente de massa, comunicação, educação, finanças, formação, projetos, etc. (SILVA, 2019).

É notório que escolas brasileiras são constituídas como um aparelho ideológico de Estado e estejam a serviço da classe dominante, contudo, seu espaço é um espaço de embates na medida em que os professores e demais profissionais da educação não necessariamente se subordinam aos poderes dominantes da forma como estes esperam, ou seja, esses profissionais não agem apenas como sinalizadores de transmissão ideológica dos detentores do poder (BEZERRA NETO, 2012).

$\mathrm{Na}$ busca por uma melhor escolarização no lugar onde residem, tanto o MST como as demais comunidades do campo como quilombolas, indígenas, caipiras, caboclos, caiçaras (jangadeiros e praieiros) e etc. têm por base relações familiares e comunitárias que lutam por políticas educacionais e sociais conduzindo consequentemente essas comunidades a um maior desenvolvimento da agricultura familiar, agroecologia e soberania alimentaria. Assim, seus territórios geralmente são 


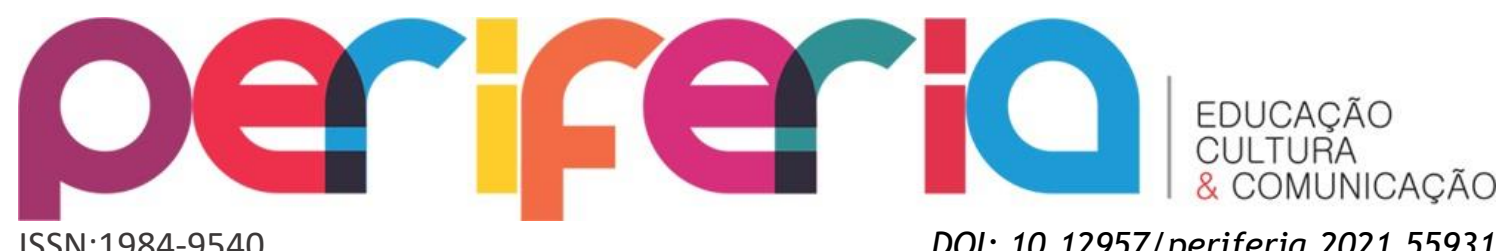

constituídos por pequenas extensões de terra produzindo predominantemente para o mercado local e regional. Essas populações e seus territórios são produtoras de alimentação saudável que vem da agricultura orgânica e da agroecologia.

É interessante pensar no significado de cidadania e cultura na educação no campo sob a perspectiva do Movimento dos Trabalhadores Rurais Sem Terra e demais comunidades que residem no campo, pois estes conceitos devem ser refletidos e seus princípios utilizados a favor dos sujeitos que delas fazem parte. Assim, o empoderamento da cidadania remete à capacidade que estes homens e mulheres do campo precisam ter para se reconhecerem como cidadãos brasileiros, detentores de direitos e deveres para eles próprios e para sua comunidade, cidade, estado e nação. Evidenciamos neste autorreconhecimento em ser um cidadão do campo ou da cidade os princípios que postulam para a concretização da cidadania trazida pelos elementos políticos, históricos, econômicos, sociais e civis.

A cultura para as comunidades do campo inicia-se na luta pela preservação de suas atividades culturais como danças, músicas, artesanatos, maneiras de cultivar a terra, formas de pescar, estratégias de preservação da fauna e flora brasileira (que retiram das florestas ou matas os recursos sem degradá-las). Contudo não se pode esquecer de que essa cultura vem dos conhecimentos historicamente construídos pela humanidade, as atividades culturais (conhecimentos locais ou regionais) das comunidades devem ser acopladas ao macro conhecimento social dos homens. É a educação que faz a mediação entre cidadania e cultura dos homens e mulheres do campo e da cidade, alicerçada nas demais linhas das ciências humanas que constroem a capacidade crítica das pessoas refletirem sobre suas práticas sociais.

\section{REFLETINDO SOBRE CIDADANIA NA EDUCAÇÃO NO CAMPO}

Falar de cidadania ${ }^{5}$ na Educação no campo, neste contexto de espoliação da classe trabalhadora constitui-se em uma responsabilidade social e ética. Demerval Saviani (2014) explica que educação é aquela que institui o homem na sociedade

\footnotetext{
${ }^{5} \mathrm{~A}$ palavra cidadania é originária do latim civitas, referente à cidade, designada pelos gregos como pólis, sendo caracterizada como um "conjunto de cidadãos, e não um território" (CARDOSO, 1993, p. 82).
} 


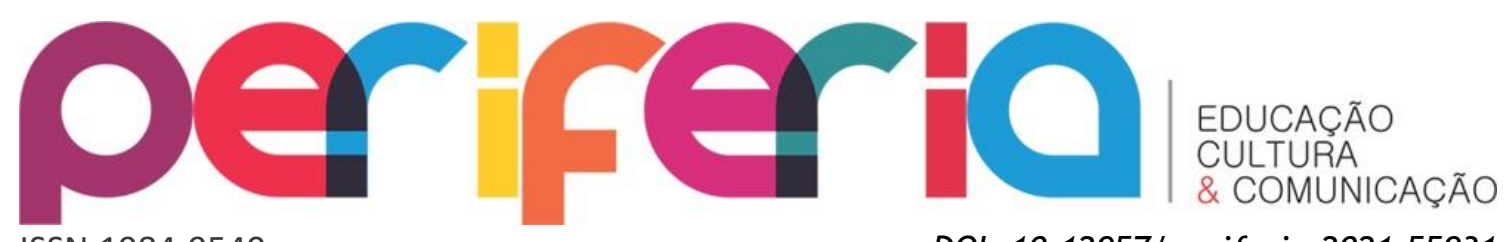

ISSN:1984-9540

DOI: $10.12957 /$ periferia.2021.55931

sendo a referência tanto para se conquistar a ética, como a cidadania, então a formação educacional do coletivo de homens resulta no principal caminho para a conquista do ponto central da trilogia: ética-educação-cidadania. Assim, temos educação localizada no centro da trilogia pela sua função de mediação no seio da prática social global (SAVIANI, 2014).

A formação educacional tem como função fazer a mediação entre o indivíduo humano e seus deveres éticos "permitindo ao homem assumir consciência da dimensão ética de sua existência com todas as implicações desse fato para a sua vida em sociedade" (SAVIANI, 2014, p. 47). Já a mediação humana com a cidadania, permite que estes indivíduos adquiram "uma consciência de seus direitos e deveres diante dos outros e de toda a sociedade" (SAVIANI, 2014, p. 48).

Assim, homens e mulheres são promovidos por meio da escolarização e formação superior. Neste sentido, promover os indivíduos residentes no campo e na cidade é torná-los aptos a conhecerem amplamente sua situação humana e social para intervir nela, transformando-a no sentido de uma expansão de liberdade cívica. Quando conhecemos os elementos que constitui nossa situação humana compreendemos a educação como uma mediadora da prática social que aponta para o constante movimento da vida.

Desta feita, o conhecimento advindo da educação crítica nos ajuda a compreender as contradições. Engels (2015) afirma que o próprio movimento humano é uma contradição, vejamos:

[...] o simples movimento mecânico de ir de um lugar para o outro só pode se efetuar de tal modo que no mesmo movimento, um corpo está no lugar e simultaneamente está em outro, um corpo está num lugar e não está nele. É o continuo pôr e a simultânea resolução dessa contradição são precisamente o movimento (ENGELS, 2015, p. 151).

As pessoas que retiram do campo sua sobrevivência estão em movimento de contradição contínuo, tal ato aponta para o critério distintivo para apreender a natureza específica de qualquer dimensão da realidade humana, sempre se perguntando a respeito de qual função social essa dimensão desempenha na reprodução do ser social. 


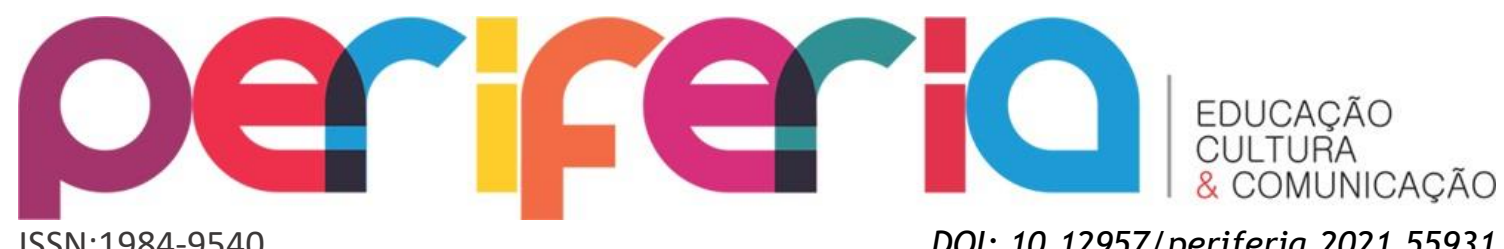

Neste sentido, Martins (2000) conceitua cidadania como a participação dos indivíduos de uma determinada comunidade em busca da igualdade em todos os campos que abarcam a realidade humana, por meio da luta pela conquista e ampliação dos direitos civis, políticos e sociais, objetivando a posse dos bens materiais, simbólicos e sociais, contrapondo-se à hegemonia dominante na sociedade de classes, o que determina novos rumos para a vida da comunidade e para a própria participação no direito a trabalhar, residir em sua própria casa e constituir família. Essa afirmação sustenta que toda forma de cidadania dos homens do campo ou cidade sempre tem seu fundamento determinado em toda forma de trabalho.

A prática social das pessoas que residem no campo na luta por cidadania e consequentemente respeito social deve levar em consideração características territoriais, econômicas e políticas das comunidades que elas pertencem, a escolarização é uma ferramenta no sentido de conseguir avançar através da luta travada pelos movimentos sociais encabeçados pela classe dos trabalhadores.

Uma vez que as populações campesinas se engajam nos movimentos sociais para manifestar sua vontade e necessidade de melhorias não somente para si, mas para todos aqueles que sofrem estagnação econômica, social e política, elas buscam para si próprias e para o coletivo a condição de cidadania. Ou seja, a educação faz com que os sujeitos que habitam e trabalham no campo brasileiro avancem como pessoas detentoras de seus direitos, para tal, lutam por políticas que tragam sua emancipação social, ainda que o os defensores do capitalismo queiram de todo jeito impedi-los de serem cidadãos políticos.

\section{REFLETINDO SOBRE CULTURA NA EDUCAÇÃO NO CAMPO: UM OLHAR PARA AS ATIVIDADES CULTURAIS}

A palavra cultura é oriunda do "verbo latino colere, que significa cultivar, criar, tomar conta e cuidar, cultura significava o cuidado do homem com a natureza" (CHAUÍ, 2000, p. 372). Em uma perspectiva marxista Trotsky (2009) explica:

Cultura é aquilo que foi criado, construído, apreendido, conquistado pelo homem no curso de toda a sua história, em contraposição ao que 


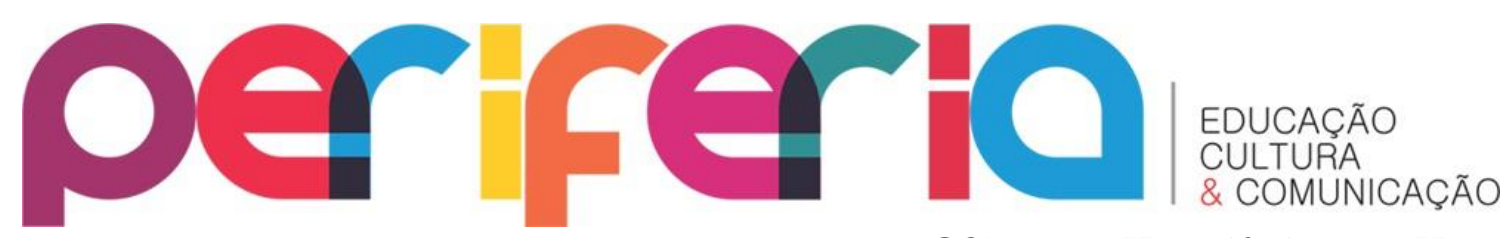

ISSN:1984-9540

DOI: $10.12957 /$ periferia.2021.55931

a natureza the deu, compreendida aí a história natural do homem como espécie animal. A ciência que estuda o homem como produto da evolução animal é a antropologia (física), Mas no momento em que o homem se separou do reino animal - e isto aconteceu quando segurou pela primeira vez os instrumentos primitivos de pedra e de madeira naquele momento começou a criação e acumulação de cultura, isto é, do conhecimento e da capacidade de todos os tipos para enfrentar e subjugar a natureza. (TROTSKY, 2009, p. 3).

Neste sentido, a herança cultural dos seres humanos remete a possibilidade de se compreender a cultura para além das classes sociais, uma cultura que pertença a toda humanidade e não a grupos ou classes específicas. De acordo com Trotsky (2009, p. 3), quando refletimos sobre "cultura acumulada, das gerações passadas, pensamos logo e sobretudo nas primeiras realizações materiais sob a forma de instrumentos, máquinas, construções, monumentos e assim por diante”. 0 autor supracitado indagase sobre isto, ou seja, a cultura, e em seguida esclarece sem dúvida, trata-se das formas materiais nas quais a cultura é colocada a partir da cultura materializada.

Esta cultura cria, com bases na natureza, o pano de fundo da vida das pessoas, do modo de viver cotidiano, do trabalho criativo. Sabemos que a parte mais preciosa da cultura é aquela que "se deposita na consciência do próprio homem: o método, os costumes, a capacidade, a habilidade que adquirimos e que se desenvolveu partindo de toda a cultura material pré-existente e que, embora se prendendo a ela, faz com que progrida de acordo com a época”. (TROTSKY, 2009, p. 4).

A cultura se desenvolveu por meio das lutas travadas pelo homem contra a natureza, pela sua existência, pela melhoria de suas condições de vida, mas partindo desse mesmo princípio também se desenvolveram as classes (TROTSKY, 2009, p. 4). No processo e adaptação à natureza, em conflito com as forças hostis, a sociedade humana vem se delineando como uma complexa organização de classes. A "estrutura classista da sociedade determinou, na medida decisiva, o conteúdo e a forma da história humana, isto é, as relações materiais e seus reflexos ideológicos. Isto significa que a cultura histórica assumiu um caráter de classe” (TROTSKY, 2009, p. 4).

A cultura como modo de vida e de luta encontra-se acoplada aos aspectos políticos, econômicos, sociais e educacionais de uma dada sociedade. Desta feita, tais aspectos tornam-se indissociáveis numa perspectiva materialista histórico-dialética e, por isso, a produção intelectual e artística se encontra historicamente construída na vida material e imaterial dos homens. 


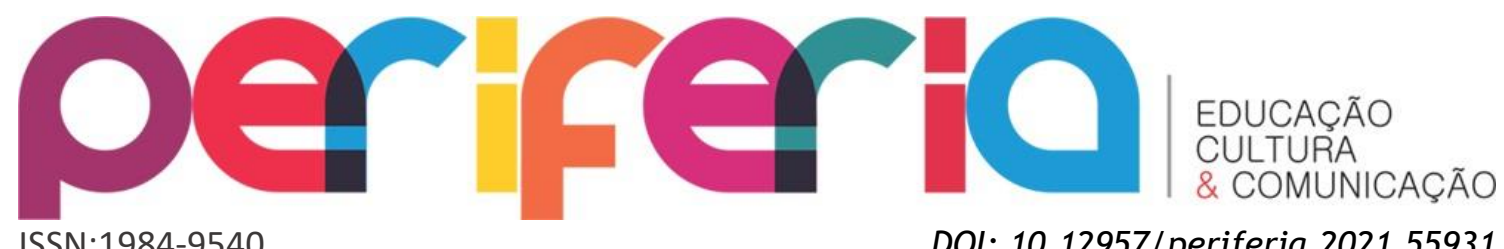

Muitas vezes, a cultura é erroneamente entendida como propriedade privada de uma única comunidade ou grupo social distinto, quando deveria ser vista como uma qualidade humana concebida no coletivo concreto de pessoas, compostas por comunidades, bairros, cidades e países. Até chegar à humanidade, ela é diretamente influenciada por situações conflitantes das classes, contudo, muitas vezes, são apenas identificadas ou representadas pelas atividades que constituem apenas segunda natureza (costumes) de uma determinada população, tipificada nas atividades artísticas, musicais, artesanais e culinárias de comunidades e regiões.

Teixeira e Dias (2011) explicam que a cultura no campo marxista aparece desde as elaborações de Marx e Engels, por mais que ambos não usassem esse termo ou tenham escrito tratados específicos sobre o tema. Contudo, evidenciamos que essas informações são recorrentes nos textos, principalmente, aliadas às discussões sobre a constituição do ser social, exemplificando, o livro A Ideologia Alemã (2007) como uma das principais referências.

Marx e Engels (2007) apresentam os principais conceitos, leis e categorias consideradas como fundamentais para a construção de sua teoria, assumidos como imprescindíveis no presente estudo. Assim, explicam os modos de vida, visão de mundo e a construção histórica da cultura a partir das relações sociais baseadas na propriedade privada dos meios de produção e na exploração alienante do homem pelo homem (MARX, ENGELS, 2007). Pois, conhecer estas relações do homem implicadas nesse "sistema é visto como necessário para que entendamos o desenvolvimento da cultura" (TEIXEIRA, DIAS, 2011, p. 126).

Magalhães (2006) explica que, no processo de emergência para a consolidação das classes, a cultura burguesa passa a ser um atributo intrinsecamente ligado à capacidade de receber educação somente erudita e extremamente tradicional. Neste sentido, os termos "ser educado" e "ser culto", "são expressões que passam a equivaler a adquirir cultura, assimilar informações, sobretudo, por meio do saber erudito [...] do mesmo modo, pode-se dizer que educação passa a significar o processo normativo de uma aprendizagem de modos e maneiras de ser culto" (MAGALHÃES, 2006, p. 94).

O capitalismo é intenso no processo vertiginoso de transformação da sociedade burguesa, sobretudo no universo campesino e na instalação de circuitos de 


\section{EDUCAÇÃO
CULTURA
\& COMUNICAÇÃO}

aprendizagens capazes de modificar os repertórios culturais que vinham perpassando o tempo, como é o caso das atividades culturais caiçaras, quilombolas, indígenas e de outras populações que são pertencentes à educação do campo. Isso vem ocorrendo tanto em espaços da educação escolar quanto da educação não escolar, na sociedade em geral, provocando diversos embates quanto à transmissão e manutenção destas atividades culturais, inclusive, atingindo de forma alienante e opressora as pessoas que atualmente vivem no campo quando comparados ao tempo das gerações passadas.

Magalhães (2006) relata que o capital tem afetado o funcionamento da sociedade em sua totalidade, usando como estratégia o bombardear das unidades ou contextos locais que valorizam a cultura historicamente construída, utilizando, para isso, não apenas a educação não escolar, mas, principalmente, aquelas que lidam com os chamados anos formativos, as crianças e os jovens. Contudo, Magalhães (2006, p. 94) remete à necessidade de compreender se existe uma cultura majoritária que passa a determinar as formas essenciais de manifestação histórica que "constituem os modos de vida regionais, raciais, feminino, infantil, juvenil, urbano e rural etc.", refletindo que a complexidade dessa relação foi descortinada pelo marxismo originário que traz o olhar conflitante entre a cultura real, o poder, a ideologia e suas formas de manutenção e superação da realidade.

Neste sentido, a cultura do homem do campo e/ou cidade encontra-se localizada no tempo social, político e econômico, constitui-se de manifestações de médio, curto e longo prazo, sendo estas sempre dinâmicas dadas nas formas anônimas ou explicitas, no entanto sempre exploradas pelas pessoas. Com o passar do tempo vão redefinido alguns aspectos, edificando outros e aderindo uma pertença social, a depender das necessidades históricas de determinados coletivos e de suas capacidades de intervenção política nos setores e instituições públicas e privadas.

Tal repertório de atividades culturais é indissociável da educação, seja ela no ambiente escolar ou não escolar. Desta feita, as atividades culturais também são associadas às experiências que estes homens e mulheres do campo desenvolveram em um meio de vida simbiótico com a fauna e flora das diversas regiões brasileiras. 


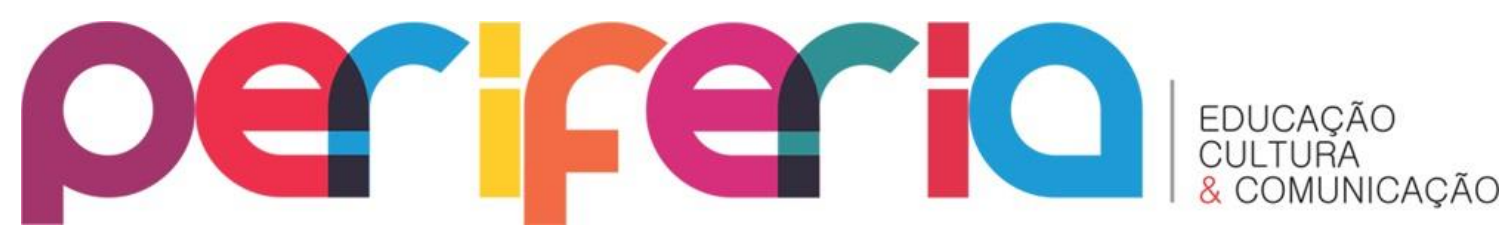

ISSN:1984-9540

DOI: 10.12957/periferia.2021.55931

\section{CONSIDERAÇÕES FINAIS}

Consideramos que a historicidade das pessoas que vivem no campo encontrase intrinsecamente ligada à produção econômica, a qual desemboca em uma totalidade social cujos aspectos políticos, sociais, econômicos, culturais e educacionais estão ligados.

Neste sentido, pensamos que cidadania e cultura na educação no campo sob a perspectiva do Movimento dos Trabalhadores Rurais Sem Terra e demais comunidades pertencentes ao campo devem ser refletidas a partir de princípios sociais e políticos. O empoderamento da cidadania remete à capacidade que estes sujeitos do campo somente poderão enxergar o mundo em sua plenitude concreta social, quando se reconhecerem como cidadãos brasileiros, detentores de seus direitos e deveres para com sua comunidade, cidade, estado e nação.

Já a cultura parte do micro para o macro, perspectiva também contemplada quando avistamos nas comunidades do campo a luta pela preservação de suas atividades culturais como danças, músicas, artesanatos, maneiras de cultivar a terra, formas de pescar, estratégias de preservação da fauna e flora brasileira, não somente para elas e suas comunidades, mas para o mundo, para os jovens e suas futuras gerações que também precisam usufruir dos conhecimentos científicos e tradicionalmente herdados. Aqui a educação torna-se inerente à comunidade, na mediação entre cidadania e cultura na vida dos indivíduos do campo e da cidade.

Notamos aí uma necessidade de estudos sobre a temática cidadania e cultura na perspectiva das populações que pertencem ao campo, principalmente naquilo que diz respeito às atividades culturais por eles herdadas ou criadas. Isso parte do pensamento de que existem várias comunidades atendidas pelas políticas da educação do campo, entendemos que esses leques de comunidades devem ter suas atividades culturais e sua cidadania estudadas a partir da mediação da educação. 


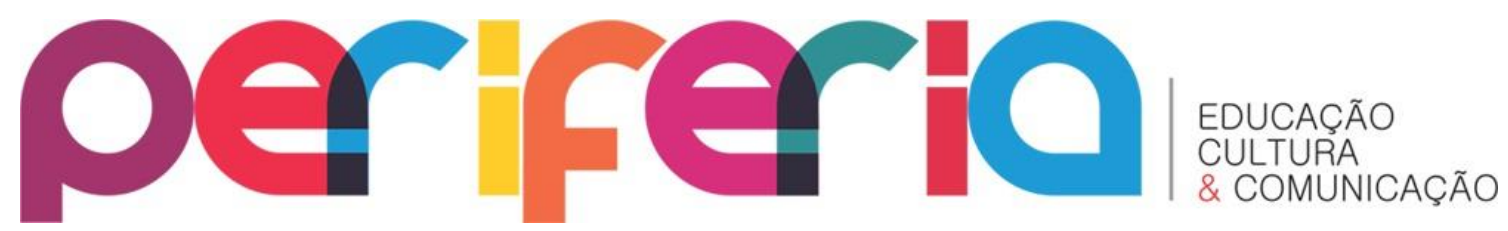

ISSN:1984-9540

DOI: 10.12957/periferia.2021.55931

\section{REFERÊNCIAS}

BEZERRA NETO, L. Educação do campo ou educação no campo? HISTEDBR On-line, Campinas, v. 2, n. 38, p. 150-168, jun de 2010.

BEZERRA NETO, L. A difícil, mas necessária relação entre os movimentos sociais e a universidade: Educação e Movimentos Sociais: práticas pedagógicas, desafios e novos rumos. In: BEZERRA NETO, L.; BEZERRA, M. C. S.; SANTOS NETO, J. L. (Org). Na luta pela terra, a conquista do conhecimento. 1. ed. São Carlos-SP: Pedro e João Editores, 2012, p. 14-59.

BRASIL. Lei de Diretrizes e Bases da Educação Nacional - LDB n 9.394, de 20 de dezembro de 1996, Brasília, MEC/SEESP, 1996.

BRASIL. Resolução $n^{\circ} 2$, de 28 de abril de 2008. Ministério da Educação. Conselho Nacional de Educação. Câmara de Educação Básica. Estabelece diretrizes complementares, normas e princípios para o desenvolvimento de políticas públicas de atendimento da Educação Básica do Campo. 2008.

CARDOSO, C. F. S. A cidade-estado Antiga. São Paulo-SP: Ática, 1993.

CHAUÍ, M. Convite à filosofia. São Paulo-SP: Ática, 2000.

ENGELS, F. Anti- Duhring. São Paulo-SP: Boitempo, 2015.

LOMBARDI, J. C. História, cultura e educação: aportes marxistas. In: LOMBARDI, J. C.; CASIMIRO, A. P. B.; MAGALHÃES, L. D. R. (org.). História, cultura e educação. CAMPINAS - SP: Autores associados, 2006, p. $169-208$.

MAGALHÃES, L. D. R. Cultura e aprendizagem social. In: LOMBARDI, J. C.; CASIMIRO, A. P. B.; MAGALHÃES, L. D. R. (org.). História, cultura e educação. CAMPINAS - SP: Autores associados, 2006, p. 93 - 107.

MARTINS, M.F. Ensino técnico e globalização: cidadania ou submissão. Campinas-SP: Autores Associados, 2000.

MARX, K.; ENGELS, F. Manifesto do partido comunista. São Paulo-SP: Edipro, 2015.

MARX, K. e ENGELS, F.A ideologia Alemã. São Paulo-SP: Boitempo, 2007.

SAVIANI, D. O lunar de sepé: paixão, dilemas e perspectivas na educação. CampinasSP: Autores associados, 2014.

SAVIANI, D. A pedagogia histórico-crítica na educação do campo. In: BASSO, J. D.; SANTOS NETO, J. L.; BEZERRA, M. C. S. (org.). Pedagogia histórico-crítica e educação 


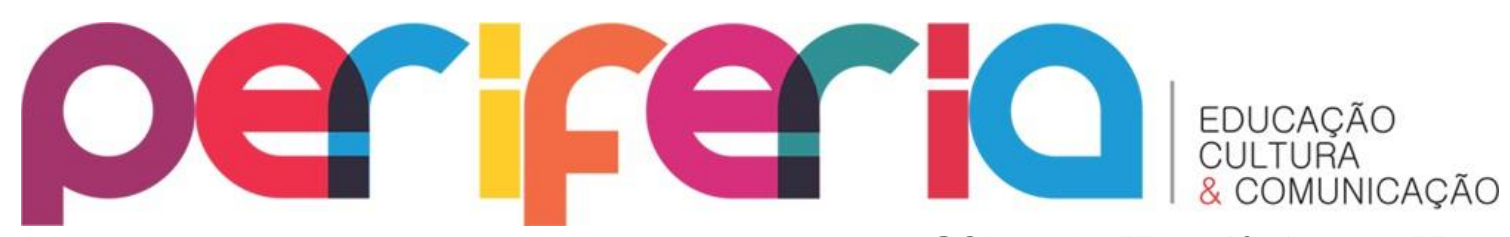

ISSN:1984-9540

DOI: 10.12957/periferia.2021.55931

no campo: história, desafios e perspectivas atuais. São Carlos-SP: Pedro \& João Editores e Navegando, 2016, p. 16-43.

SILVA, J. L. L. Princípios educativos do MST: estratégias e caminhos para uma formação contra- hegemônica. In: SANTOS, A. R.; SILVA, G. J.; OLIVEIRA, J. M. S.; COELHO, L. A. (Org.). Movimentos sociais e educação: políticas e práticas. Ilhéus-BA: Editus, 2019, p. 57-72.

TEIXEIRA, D. R.; DIAS, F. B. M. Marxismo e cultura: contraponto às perspectivas pósmodernas. Revista Digital do Paideia, v. 2, n. 2, p. 120-140, nov de 2011.

TROTSKY, L. Cultura e socialismo. Cartilha da seção brasileira da internacional revolucionária juventude (IRJ). São Paulo- SP: Editora da IRJ, 2009.

ZANELLA, L. C. H. Metodologia de pesquisa. Florianópolis-SC: Departamento de Ciências da Administração / UFSC, 2013. 